\title{
RÉGUA E COMPASSO NO ENSINO PRIMÁRIO? CIRCULAÇÃO E APROPRIAÇÃO DE PRÁTICAS NORMATIVAS PARA AS MATÉRIAS DE DESENHO E GEOMETRIA
}

\author{
Maria Célia Leme da Silva \\ Universidade Federal de São Paulo, Brasil.
}

$\cos 80$

\begin{abstract}
Resumo
No presente artigo discute-se o uso da régua e compasso nas matérias de Geometria e de Desenho no ensino primário do período da Primeira República. Os programas de ensino dos Estados de São Paulo, Minas Gerais, Sergipe, Goiás e Rio Grande do Sul constituem fontes privilegiadas de análise. Infere-se que construções com régua e compasso podem representar práticas pedagógicas para o ensino de Geometria e de Desenho no ensino primário, para além do Estado de São Paulo, considerado como modelo.

Palavras-chave: ensino de geometria, ensino de desenho, grupos escolares, construções geométricas, régua e compasso.
\end{abstract}

\section{RULER AND COMPASS IN ELEMENTARY EDUCATION? CIRCULATION AND APPROPRIATION OF NORMATIVE PRACTICES IN THE SUBJECT OF DRAWING AND GEOMETRY}

\begin{abstract}
This article discusses the use of a ruler and compass in the subject of Geometry and Drawing in primary school for the period of the First Republic. Educational programs of the states of São Paulo, Minas Gerais, Sergipe, Goiás and Rio Grande do Sul are privileged sources of analysis. It is inferred that constructions with ruler and compass can represent pedagogical practices for teaching Geometry and Drawing in elementary school, in addition to the state of São Paulo, considered as a model.

Key-words: teaching of geometry, teaching of drawing, elementary school, geometric constructions, ruler and compass.
\end{abstract}




\section{REGLA Y COMPÁS EN LA EDUCACIÓN PRIMARIA? CIRCULACIÓN Y APROPIACIÓN DE PRÁCTICAS NORMATIVAS EN LA MATERIA DEL DIBUJO Y GEOMETRÍA}

\section{Resumen}

Este artículo aborda el uso de una regla y un compás en la materia del Dibujo y Geometría en la escuela primaria durante el período de la Primera República. Los programas educativos de los Estados de São Paulo, Minas Gerais, Sergipe, Goiás y Rio Grande do Sul son fuentes privilegiadas de análisis. Se infiere que las construcciones con regla y compás pueden representar prácticas pedagógicas para la enseñanza de la Geometría y del Dibujo en la escuela primaria, además del Estado de São Paulo, considerada como modelo.

Palabras-clave: enseñanza de la geometría, enseñanza del dibujo, escuela primaria, construcciones geométricas, regla y compás.

\section{REGLE ET COMPAS DANS L'ENSEIGNEMENT PRIMAIRE? CIRCULATION ET APPROPRIATION DES PRATIQUES NORMATIVES DANS LE MATIERE DE LE DESSIN ET DE LA GEOMETRIE}

\section{Résumé}

Cet article discute l'utilisation d'une règle et un compas dans le matière de la Géométrie et le Dessin à l'école primaire pour la période de la Première République. Les programmes éducatifs des États de São Paulo, Minas Gerais, Sergipe, Goiás et Rio Grande do Sul sont des sources privilégiées d'analyse. On en déduit que les constructions avec règle et au compas peuvent représenter des pratiques pédagogiques pour l'enseignement de la Géométrie et de Dessin à l'école primaire, en plus de l'état de São Paulo, considéré comme un modèle.

Mots-clé: l'enseignement de la géométrie, l'enseignement de le dessin, école primaire, des constructions géométriques, règle et au compas. 


\section{Considerações iniciais}

Égua e compasso no ensino primário? Muito provavelmente a primeira reação a tal pergunta seja de surpresa. Instrumentos usados para fazer construções geométricas, como régua, compasso, esquadro e transferidor remetem para as práticas da disciplina escolar Desenho Geométrico, presente no ensino secundário da primeira metade do século 20 e que após a lei n. 5.692, de 1971, foi substituída por Educação Artística. Construções de retas paralelas e perpendiculares, ângulos, triângulos, quadriláteros, polígonos, traçados com instrumentos geométricos, constituem exemplos de exercícios que caracterizam esta disciplina. Desta forma, justifica-se o estranhamento em associar o uso de régua e compasso aos anos iniciais escolares.

No entanto, na história da educação matemática, tais práticas conformam a Geometria e o Desenho no ensino primário brasileiro. Este é o objetivo do presente texto: evidenciar como régua, compasso e demais instrumentos ligados às construções geométricas tomam parte de uma das rubricas presentes no ensino primário na Primeira República. Para além dos objetivos deste artigo, cabe destacar que o estudo inclui-se em dimensão recente da pesquisa no campo denominado Educação Matemática: a história da educação matemática.

Schubring (2012) analisa a produção internacional da História da Educação Matemática e assinala como referência da constituição da área o estabelecimento do Topic study group: the history of teaching and learning mathematics, no âmbito do International Congress on Mathematical Education - ICME, no ano 2004, em Copenhaguen. No Brasil, tais estudos e investigações têm ganhado reconhecimento enquanto campo específico de produção científica. Pode-se dizer que a realização do $1^{\circ}$ Encontro Nacional de Pesquisa em História da Educação Matemática, em Vitória da Conquista, Bahia, em 2012, denota um marco desta produção em nível nacional.

Entretanto, pouco mais de uma década de investigação constitui tempo escasso para a dimensão do saber a ser construído, ou seja, produzir histórias sobre como aconteceu o ensino de Matemática em diferentes níveis de ensino e nos diversos momentos históricos. Praticamente pouco se conhece sobre o passado do ensino de Matemática, componente curricular que participa desde sempre nos processos educativos e em instituições de ensino.

Considerando a história do ensino de Matemática nos cursos primários, o inventário ${ }^{1}$ de pesquisas de histórias da educação matemática produzidas sobre os anos iniciais de escolarização e referenciadas nos trabalhos publicados nos anais do $1^{\circ}$ Enaphem indica que os estudos ganharam interesse a partir do final da primeira década do século 21 . As temáticas em destaque denunciam a marcante presença da Aritmética, seguida de estudos sobre a Geometria. Outra característica realçada é a discussão das metodologias de ensino e das renovações pedagógicas como ingredientes determinantes para a compreensão de uma educação matemática no curso primário em cada período histórico. Pode-se dizer que o método tradicional, o método intuitivo ou de lições de coisas da

\footnotetext{
${ }^{1} \mathrm{O}$ inventário de histórias produzidas constitui subcapítulo de livro provisoriamente intitulado Handbook of research on the history of mathematics education in Brazil que está sendo elaborado pela equipe organizadora do I Enaphem. 
Escola Nova ou Escola Ativa, assim como as propostas de uma matemática modernizadora durante o Movimento da Matemática Moderna, cumpriram papel crucial na compreensão das diferentes aritméticas e geometrias presentes no ensino primário, ou seja, a presença da Pedagogia ou da Psicologia são elementos integrantes na configuração da Matemática escolar dos anos iniciais.

Neste texto, enfatizam-se dois desses saberes: Geometria e Desenho. Delimita-se o marco da Primeira República como recorte temporal de organização e estruturação do ensino primário no que vem a ser nomeado por grupos escolares ${ }^{2}$ e elegem-se cinco Estados: São Paulo, Minas Gerais, Sergipe, Goiás e Rio Grande do Sul. Os Estados escolhidos correspondem àqueles em que já se pode obter documentação junto ao repositório do projeto $A$ constituição dos saberes elementares matemáticos: a Aritmética, a Geometria e o Desenho no curso primário em perspectiva histórico-comparativa (18901970).

Pesquisas (Leme da Silva, 2014; Valente, 2012) já desenvolvidas pelo Ghemat ${ }^{3}$, especificamente no Estado de São Paulo, apontam que as normatizações para o ensino de Geometria e de Desenho nos programas dos grupos escolares paulistas mantiveram uma proximidade significativa ao longo do período imperial e nas duas primeiras décadas de sua criação. A partir do final do século 19 e início do século 20 , a articulação entre estes saberes se rompeu e as trajetórias das duas matérias seguiram independentes. No entanto, cada um dos saberes carrega marcas da sua união de longo tempo na história da educação matemática.

Uma herança identificada na constituição da matéria de Geometria dos grupos escolares paulistas é a participação das construções geométricas com régua e compasso em práticas normativas ao longo de toda a metade do século 20 . Em que medida tal proposta configura-se como restrita ao Estado de São Paulo, pólo de vanguarda na criação do modelo de grupos escolares, ou circula e se incorpora como proposta inovadora nos demais Estados? Em outras palavras, como estudos históricos locais da educação matemática podem dialogar na construção de representações globais?

Pretende-se, assim, estender a compreensão das normatizações dos programas de Geometria e de Desenho nos cinco Estados referenciados anteriormente no período de implementação dos grupos escolares. Valente (2013, p. 42) sugere que os "estudos históricos comparativos constituem uma especificidade, ao que parece, da discussão mais geral sobre a retomada do tema da pesquisa histórica de caráter global". Amparado nos estudos de Roger Chartier, Valente destaca que "o que importa é a eleição de um marco de estudo capaz de tornar visíveis as histórias concetadas que relacionaram populações, culturas, economias e poderes" (Chartier, 2007, apud Valente, 2013, p. 43) e sintetiza, como exemplo de investigações acerca do ensino primário, "estudos da matemática em nível primário, em todo e qualquer grupo escolar, instalados em qualquer Estado brasileiro não poderão abdicar do diálogo com a organizaçao paulista do curso primário, modelo que se espalha pelo Brasil a partir de finais do século 19" (Valente, 2013, p. 44).

\footnotetext{
${ }^{2}$ A reunião de escolas foi instituída em 1893 e configurou um novo tipo de escola primária denominada de grupo escolar: típica escola urbana, moderna e de melhor qualidade (Souza, 2009, p. 64)

${ }^{3}$ Grupo de Pesquisa de História da Educação Matemática no Brasil: http://www.unifesp.br/centros/ghemat. Hist. Educ. [Online] 
Antes de analisar as relações entre a Geometria e o Desenho na constituição dos grupos escolares nos diferentes Estados, apresentam-se considerações de como esses saberes se inseriram nas escolas de primeiras letras no decorrer do Império.

É preciso esclarecer que a Geometria integrou os saberes que os professores deviam ensinar na escola de primeiras letras desde a primeira lei de instrução pública no Brasil, de 15 de outubro de 1827: ora como Noções gerais de geometria prática, ora como Princípios elementares de geometria. Já o Desenho foi inserido mais tardiamente, a partir do decreto n. 7.247, de 19 de abril de 1879, como Elementos de desenho linear e precede ao estudo de Geometria.

Pode-se dizer que ao longo do século 19 a ligação entre as matérias de Desenho e Geometria é muito próxima, tanto nas legislações que regem a escola de primeiras letras do Império, quanto nos primeiros livros didáticos que traziam propostas para 0 desenvolvimento desses novos saberes, para além do tradicional ler, escrever e contar. O Desenho Linear foi introduzido pelo traçado de figuras geométricas e a Geometria representada pelos desenhos, ou seja, trata-se de saberes que seguem trajetórias similares e interligadas na construção da cultura escolar do ensino primário.

Destaca-se, ainda, que os livros e manuais inventariados ${ }^{4}$ até o momento não indicam a presença do traçado com instrumental geométrico para os anos iniciais. As figuras geométricas são representadas e reproduzidas pela observação, à mão livre. Valente (2012, p. 90) analisa a obra Desenho linear ou elementos de geometria prática popular, de Abílio Cesar Borges, de 1882, e conclui que ele sedimenta a organização de uma Geometria para a escola de primeiras letras como Desenho Linear, desenho de linhas. Neste caso, atendendo às normativas oficiais, o Desenho Linear faz escola como Geometria.

\section{Pólo de vanguarda: o Estado de São Paulo e as construções geométricas}

O Estado de São Paulo foi pioneiro na reestrutução da instrução pública, logo após a Proclamação da República. A escola de primeiras letras do Império cedeu lugar aos grupos escolares, criados em 1893. O novo modelo de escola primária simbolizou a modernização do ensino e se tornou referência para os outros Estados. Para além da nova organização física e administrativa do ensino primário nos grupos escolares, há também uma nova apresentação dos programas de ensino. Se antes o controle do governo recaía apenas sobre o arcabouço estrutural do programa - o rol das matérias a serem ensinadas -, a partir de então prescrições cada vez mais detalhadas se voltam para a normatização das rotinas escolares (Souza, 2009).

O primeiro programa de ensino dos grupos escolares paulistas foi elaborado por Oscar Thompson, Benedito Tolosa e Antonio Rodrigues Alves ${ }^{5}$ e oficializado pelo decreto n. 248 , de 26 de junho de $1894^{6}$. As rubricas Desenho Linear ou Geometria Prática não são mais empregadas, entretanto, as matérias de Geometria e Desenho permanecem

\footnotetext{
${ }^{4}$ Foi feito um inventário de livros e manuais sobre Geometria e Desenho no ensino primário referente ao período do Império a partir de buscas em sebos e bibliotecas de São Paulo e Rio de Janeiro.

${ }^{5}$ Oscar Thompson e Bendito Maria Tolosa atuavam como professores na Escola Modelo anexa à Escola Normal e Antonio Rodrigues Alves era inspetor de ensino (Souza, 2009, p. 83)

${ }^{6}$ Decreto n. 248, de 26 de julho de 1894 - Approva o regimento interno das escolas públicas. Assinado por Bernardino de Campos, presidente do Estado de São Paulo. 
embricadas, em especial nos dois primeiros anos. O Desenho, presente desde o $1^{\circ}$ ano, começa com os traçados de linhas horizontais, verticais, ângulos. A Geometria se inicia no ano seguinte, $2^{\circ}$ ano, e trata de figuras geométricas, como triângulos e quadriláteros, com grande similaridade de conteúdos presentes em Desenho, porém, a construção é proposta explicitamente na matéria de Desenho, onde se lê: "construção do triangulo retângulo, do triangulo isósceles, do triangulo eqüilátero. Quadrados: diagonais e diâmetros: sua construção. Diferentes métodos de construção - pelos lados, pelos diâmetros, pelas diagonais" (Programa de Desenho, 1894). Não há, nas orientações normativas, indicações de como devem ser realizadas tais construções.

No intuito de examinar o primeiro programa nas suas intenções, analisam-se as publicações de seus autores em revistas pedagógicas da época. Um dos autores do programa de 1894 de São Paulo, Benedito Tolosa, assinou o artigo Primeiras lições de desenho na Revista Publica, em 1895. O artigo detalha uma sequência de lições para o ensino de Desenho, no formato de perguntas e respostas aos alunos. As construções de retas paralelas, perpendiculares, triângulos, quadrados são propostas à mão livre, sem uso de instrumentos geométricos. Tolosa (1895) deixou claro que as sugestões expostas se inspiravam na pedagogia norte-americana e que não se encontravam em compêndio algum de Desenho Linear (p. 167).

Tudo indica que o programa dos grupos escolares paulistas mantém continuidade em relação às matérias de Desenho e Geometria, bem como se nota que permanecem construções de figuras geométricas à mão livre em Desenho nas prescrições legislativas. A novidade se apresentou na publicação de livro destinado ao ensino de Geometria e não de Desenho, publicado no ano de 1894, Primeiras noções de geometria prática, de Olavo Freire. A edição de 1907 traz uma seção denominada Algumas opiniões sobre a primeira edição, extraídas de jornais:

Jornal do Commercio, 29 de março de 1895:

Os Srs. Alves \& $C^{\text {ia }}$ acabão de editar um livro muito útil, do Sr. Olavo Freire. Intitula-se Primeiras noções de Geometria Prática e dá ao ensino de geometria elementar a facilidade que os estudantes não encontrão em outros compêndios. O Sr. Olavo Freire, pela clareza da sua exposição e pela excellencia do methodo que adoptou, soube tornar o seu livro uma obra didactica de mérito verdadeiramente excepcional. Por elle a geometria elementar póde ser ensinada com grande vantagem nas escolas de instrucção primária, e sabem todos quanto o conhecimento de geometria impõe-se hoje a todas as profissões. (Freire, 1907, p. 9)

A obra, diferentemente de outros livros, utiliza as construções de figuras geométricas com régua e compasso desde o segundo capítulo. Apresenta-se como um roteiro de construções geométricas, caracterizado pelo desenho geométrico. A presença de instrumentos no traçado geométrico marca uma ruptura na relação de proximidade entre Desenho e Geometria, pois os traçados de figuras geométricas até então propostos em manuais de Desenho e Geometria consideravam o traçado à mão livre. Pode-se dizer que se insere uma nova prática no estudo da Geometria: o manuseio dos instrumentos e a aprendizagem de sequências para a realização das construções geométricas diferenciam-se, significativamente, de práticas pedagógicas anteriores. 
Vale observar que Rosa de Fátima Souza (2009), no livro Alicerces da pátria: história da escola primária de São Paulo (1890-1976), apresenta provas de Geometria realizadas por alunos do $3^{\circ}$ ano do Grupo Escolar de Sorocaba, cidade do interior de São Paulo, encaminhadas pelo diretor da escola à Inspetoria Geral da Instrução Pública em 1896. As provas foram encontradas no Arquivo Público de São Paulo e pede-se a solução de um problema: "Traçar a bisectriz de um ângulo ou divid-o em duas partes iguaes", em que a aluna resolve com traçados que evidenciam o emprego de régua e compasso. Tanto o problema como a solução são idênticos aos apresentados no livro de Olavo Freire.

Tudo leva a crer que práticas de construções geométricas com instrumentos participam como problemas da matéria de Geometria nos primeiros grupos escolares paulistas, mesmo sem a sua explicitação nos programas de ensino. O período da Primeira República em São Paulo é marcado por várias reformas da instrução pública e mudanças de programas, em especial, nos anos de 1894, 1905, 1918, 1921 e 1925.

Destaca-se, ainda, que a reforma de ensino de 1905, regulamentada pelo decreto $\mathrm{n}$. $1.281^{7}$, rompeu definitivamente com a articulação entre as matérias de Desenho e Geometria, em especial pela nova abordagem do Desenho, que se caracteriza como desenho ao natural. A separação pauta-se na divisão entre real e abstrato. De um lado, o Desenho passa a se comprometer com a representação do natural, de objetos concretos e, de outro, a Geometria, ciência desde sempre comprometida com os entes geométricos abstratos e com o rigor. Mas não se trata apenas de uma divisão: uma não auxilia mais a outra (Leme da Silva, 2014).

As reformas seguintes mantém a divisão entre Desenho e Geometria, porém, evidenciam os instrumentos geométricos nas prescrições práticas da matéria de Geometria. É no programa da reforma de 1918 , decreto n. $2.944^{8}$, que pela primeira vez se lê para $\circ 3^{\circ}$ ano primário a orientação "traçado de linhas com uso do compasso". A mesma indicação está presente na reforma de 1921 , decreto n. $3.356^{9}$, para o $2^{\circ}$ ano, já que a referida reforma reduz o ensino primário para dois anos. Finalmente, em $1925^{10}$, a presença de instrumentos de construção na matéria Geometria é explicita e detalhada no programa do $3^{\circ}$ ano, em que se observa "traçado da circunferência a mão livre e a compasso. Fazer um ângulo igual ao outro com compasso e transferidor. Traçado de perpendiculares com auxilio de régua, esquadro e compasso. Traçado de triângulos com instrumentos" (Programa de 1925).

Em síntese, a matéria de Geometria, nos programas paulistas para os grupos escolares, configura-se na Primeira República por uma Geometria pautada em

\footnotetext{
${ }^{7}$ Decreto n. 1.281, de 24 de abril de 1905 - Aprova e manda observar o programa de ensino para os grupos escolares e escolas modelo. Assinado por Jorge Tibiriçá - J. Cardoso de Almeida.

8 Decreto n. 2.944, de 8 de agosto de 1918 - Aprova o regulamento para a execução da lei n. 1.579 , de 19 de dezembro de 1917, que estabelece diversas disposições sobre a Instrução Pública do Estado. Assinado por Altino Arantes - Oscar Rodrigues Alves.

${ }^{9}$ Decreto n. 3.356, de 31 de maio de 1921 - Regulamenta a lei n. 1.750, de 8 de dezembro de 1920, que reforma a instrução pública. Assinada por Washington Luis Pereira de Sousa - Alarico Silveira. As principais medidas da reforma de 1920 foram: redução do ensino primário para dois anos de duração nas escolas urbanas e rurais e a criação do ensino médio correspondente ao $3^{\circ}$ e $4^{\circ}$ anos do curso primário existente até então (Souza, 2009).

${ }^{10}$ Ato de 19 de fevereiro de 1925 da Secretaria de Estado dos Negócios do Interior, assinado por José Manuel Lobo. 
construções geométricas com régua e compasso. Traçados de Desenho Geométrico são inseridos nas normatizações no período e se constituem como práticas de ensino e aprendizagem de uma Geometria escolar para o curso primário. Certamente a proximidade com o desenho à mão livre de tempos passados cumpre fator relevante nessa herança de traçar figuras geométricas como prática pedagógica da matéria de Geometria. Porém, tal continuidade se reveste de rupturas e inovações, como a inserção de traçados com instrumentos geométricos.

Ao tecer considerações sobre o programa proposto aos grupos escolares de São Paulo, Rosa Fátima de Souza julga-o como ambicioso e impraticável, ao constatar que "já na virada do século 20, relatórios de inspetores e diretores de grupos escolares do Estado de São Paulo davam a conhecer as dificuldades do cumprimento integral do programa de ensino" (2009, p. 12). Entretanto, apesar das críticas e ressalvas à sua adoção, o modelo apresentado para os grupos escolares no Estado de São Paulo é considerado um dos indicadores da modernização educacional paulista e se tornou referência para outras regiões do país:

No início do século 20, governos e responsáveis pela educação em vários
Estados brasileiros viam o sistema público implantado em São Paulo como
uma referência, um sistema modelar a ser adotado, com ou sem reparos,
nas mais diferentes regiões do país. A força dessa representação, ainda
pouco explorada na historiografia da educação brasileira, ancorava-se nos
ideais liberais de educação, na crença no poder da escola e no modo de
conceber o desenvolvimento regional e nacional atrelado à modernização
educacional. (Souza, 2009, p. 69)

Os programas paulistas circularam e foram apropriados em diferentes Estados. Assim, a análise das normatizações de alguns Estados permite investigar as práticas de construções e traçados nas matérias de Desenho e Geometria em outros espaços. A prescrição sobre o uso da régua e compasso configura uma representação das práticas pedagógicas normativas para o ensino de Geometria? Em que medida as relações de proximidade entre Desenho e Geometria se configuram como particulares do Estado de São Paulo ou extrapolam o Estado?

\section{As normativas oficiais do Estado de Minas Gerais: desenho, geometria, régua e compasso}

O estudo de Araújo (2012) examina a escola primária de Minas Gerais tomando como documento as mensagens dos presidentes de Estado. O pesquisador destaca que a primeira vez que o tema grupos escolares apresenta-se nas mensagens mineiras data de 1903, apesar de em 1898 ter sido objeto de discussão na Assembleia Legislativa do Estado de Minas Gerais.

Pouco tempo depois, o ano de 1906 marca a instauração da política pública mineira em torno dos grupos escolares, concebida como uma forma superior de escola primária, ao lado da escola-modelo, e que convive com as demais modalidades, como a escola isolada quantitativamente hegemônica (Araújo, 2012). De outra parte, os dados relativos à difusão do ensino primário em 1922 anunciam o Estado de Minas Gerais com 171 grupos escolares, muito próximo do Estado de São Paulo, com 194 grupos escolares (Araújo, 2012). 
Ao analisar as legislações que normatizam o ensino primário no Estado de Minas Gerais, identifica-se uma primeira mudança significativa na sua configuração após o estabelecimento do modelo seriado de grupo escolar em 1906, que significa a presença da Geometria e do Desenho. Como exemplo, a lei n. $221^{11}$, de 1897 , que contém disposições relativas à instrução primária, não indica a Geometria nem o Desenho como disciplinas a comporem o ensino primário.

Já em 1906 o decreto n. $1.947^{12}$ apresenta o programa de ensino primário de maneira detalhada e com instruções. Geometria e Desenho é a denominação do bloco de instruções que propõe que as noções devem estar baseadas em coisas concretas, como objetos da classe, e o desenho deve habilitar o aluno para a reprodução de objetos, graduando as dificuldades. No programa, a disciplina é proposta somente nos terceiros e quartos anos e com a mesma designação Geometria e Desenho. Inicia-se pelo estudo de corpo, superfície, face, aresta e vértice, classificação de linhas, ângulos, meios empregados pelos carpinteiros para traçarem curva se retas, régua comum, o compasso e a corda, medir e calcular distâncias a olho (Programa, terceiro ano, 1906,). No quarto ano propõem-se construir triângulos, quadriláteros, polígonos e objetos simples, comuns e ao natural sem evidenciar qual instrumento deva ser usado.

O programa de $1912^{13}$ é idêntico ao de 1906 e muito similar ao programa de $1916^{14}$, que se mostra mais pormenorizado que os anteriores. Nos instrumentos mantém régua, compasso e acrescenta esquadro e duplo-decímetro. As construções geométricas são detalhadas, como construir um ângulo igual ao outro, dividir um ângulo ao meio, tirar uma paralela a uma reta por um ponto dado, etc. (Programa, terceiro ano, 1916), sem, contudo, abandonar o desenho de cópia de objetos usuais, do natural.

Por fim, o programa de $1925^{15}$ exibe novas alterações no que diz respeito à Geometria e ao Desenho. Essas matérias integram todos os anos escolares, do primeiro ao quarto ano. Vale destacar que no horário que acompanha os programas, no primeiro e segundo anos, leem-se duas aulas semanais de Desenho e nos terceiros e quartos anos Desenho e Geometria com três aulas semanais. No primeiro ano destacam-se os traçados a lápis de retas, curvas e exercícios sobre coisas e objetos, à mão livre. No segundo ano observa-se traçar linhas empregando régua e compasso, além de cópia de objetos comuns, do natural. Os programas do terceiro e quarto anos seguem, em linhas gerais, a proposta dos anteriores.

A união entre Desenho e Geometria segue até o final da Primeira República. Na organização dos programas convivem bem as propostas de construção de figuras geométricas com régua e compasso e as cópias de desenhos de objetos comuns, ao natural. Ressalta-se que no momento de ampliação da disciplina para quatro anos, o

11 Lei n. 221, de 14 de setembro de 1897. Assinada por Chrispim Jacques Bias Fortes. Dr. Henrique Augusto de Oliveira Diniz.

12 Decreto n. 1.947, de 30 de setembro de 1906, aprova o programa do ensino primário. Assinado por João Pinheiro da Silva. Manoel Thomaz de Carvalho Britto.

${ }^{13}$ Decreto n. 3.405, de 15 de janeiro de 1912, aprova o programa de ensino dos grupos escolares. Assinado por Julio Bueno Brandão. Delfim Moreira da Costa Pinheiro.

14 Decreto n. 4.508, de 19 de janeiro de 1916, aprova o programa do ensino primário. Assinado por Delfim Moreira da Costa Pinheiro. Americo Ferreira Lopez.

15 Decreto n. 6.758, de $1^{\circ}$ de janeiro de 1925 , aprova os programas do ensino primário. Assinado por Fernando Mello Vianna. Sandoval Soares Azevedo.

Hist. Educ. [Online] $\quad$ Porto Alegre $\quad v .18$

n. 44

Set./dez. 2014

p. $79-97$ 
primeiro realiza um traçado à mão livre, porém, desde o segundo ano as construções devem incluir instrumentos como régua e compasso.

De outra parte, apesar da organização conjunta, na descrição de conteúdos no programa de 1925 também se identifica uma divisão no terceiro e quarto ano entre conteúdos de Desenho e Geometria: para a Geometria segue orientação de traçados de figuras geométricas com régua e compasso e para o Desenho cabem à cópia de objetos comuns, do natural, inclusive sem auxílio de instrumentos como é explicitado no programa do $3^{\circ}$ ano.

De todo modo, tudo indica que a inserção da Geometria e do Desenho nos programas dos grupos escolares de Minas Gerais se fez com instrumentos de construção, como régua e compasso, num primeiro momento destinado aos anos finais do ensino primário. Somente em 1925 a proposta ganhou uma gradação ao longo dos quatro anos e manteve os instrumentos de construção a partir do segundo ano.

\section{As normativas oficiais do Estado de Sergipe: desenho, geometria, régua e compasso}

Jorge Carvalho do Nascimento (2012) apresenta uma reflexão acerca da escola primária em Sergipe. Desde as primeiras páginas destaca que o modelo de grupos escolares de São Paulo era visto por dirigentes políticos sergipanos como uma possibilidade de resolver o problema da escola primária no Estado.

A criação da escola primária seriada ocorreu pelo decreto n. $563^{16}$, de 1911 , que definiu dois modelos para o ensino no Estado de Sergipe: a escola isolada e a escola seriada, esta última funcionando nos grupos escolares. Nascimento (2012) destaca a atuação do médico Helvécio de Andrade, duas vezes diretor da instrução pública, como fundamental para o processo de implantação dos grupos escolares em Sergipe:

O entusiasmo que o professor Helvécio de Andrade reiterava sempre em relação ao projeto reformador de São Paulo fez com que autorizasse a viagem àquele Estado, de vários intelectuais sergipanos com o objetivo de conhecer as reformas do ensino ali implementadas. (Nascimento, 2012, p. 214)

O decreto de 1911 estabeleceu uma nova organização para o ensino no Estado, criou os grupos escolares em Sergipe e foi concebido sob a inspiração do professor Carlos da Silveira ${ }^{17}$, vindo de São Paulo para reformar a instrução pública sergipana.

Como as relações próximas entre Sergipe e São Paulo se evidenciam nos saberes de Desenho e Geometria? Ivanete Batista dos Santos (2013) analisa o quadro de disciplinas dos grupos escolares nas primeiras legislações após sua implantação, nos anos de 1911 até 1916, e constata que não há muita alteração no rol de disciplinas, a não ser em relação à matéria denominada Desenho em 1911, que em 1912 passou a ser denominada de Desenho Linear. Identifica, ainda, outra alteração em relação ao Desenho Linear no ano de 1916, que apareceu com o seguinte indicativo: Desenho Linear e Noções de Geometria Plana.

${ }^{16}$ Decreto n. 563, de 12 de agosto de 1911. Assinado por José Rodrigues da Costa Doria e José Alipio de Oliveira.

${ }^{17}$ Carlos da Silveira foi diretor do Grupo Escolar da Avenida Paulista (Nascimento, 2012). 
Examinando as legislações que antecedem a implantação dos grupos escolares em Sergipe, observa-se a presença da disciplina de Geometria Prática e Desenho Linear em 1890, já incluindo na referida normatização as lições de coisas como disciplina, o que evidencia a apropriação da nova vaga pedagógica do final do século 19 e início do século 20. Em 1901 um novo programa alterou a nomenclatura da disciplina, que passou a ser apenas Desenho Linear. Mesmo sem ter acesso aos programas de tais matérias de ensino nos diferentes decretos, é possível inferir que Desenho Linear e Geometria caminham de maneira próxima: elas estão juntas em 1890 e depois voltam a estar na mesma rubrica em 1916.

O programa detalhado data de 1917 e é assinado por Helvécio de Andrade, como diretor interino. Nele, o Desenho está presente nos quatro anos, sendo que no primeiro ano são sugeridos três passos iniciais para o seu ensino. Destaca-se o primeiro passo: traçar no quadro negro e depois no papel circunferências, pirâmides, cubos, triângulos, ângulos, linhas-retas, curvas, quebradas, espirais, paralelas, etc. Obedecer a ordem indicada e não começar por linhas (Programa de 1917). Os próximos passos sugerem o desenho natural, de reprodução, de folhas, frutas, de imaginação, de paisagens. $O$ segundo e terceiro ano, seguem a orientação de desenho natural, articulados com objetos geométricos, como oval, quadrado, circunferências e no quarto ano, desenho geométrico no quadro negro (Programa de 1917).

Diferentemente dos Estados de São Paulo e Minas Gerais não há menção, nas normas e orientações do programa, de construções geométricas com instrumentos. Entretanto, há, no quarto ano, a indicação Desenho Geométrico, que normalmente é designado para as construções com régua e compasso. De todo modo, como sua indicação é somente no último ano, é provável que a terminologia não designe o uso de construções com tais instrumentos.

Há, também, no programa de 1917, ao final, uma relação de livros adotados e entre eles encontra-se Lições de coisas de Ruy Barbosa (para o professor). Tudo indica ser o manual Primeiras lições de coisas. Manual de ensino elementar para uso dos pais e professores publicado, originalmente, por Norman Allison Calkins nos Estados Unidos, em 1861, traduzido para o português por Rui Barbosa em 1886 e publicado pela Editora Imprensa Nacional. O manual é considerado um marco na tentativa de implantar o método das lições de coisas no ensino brasileiro, também referenciado como método intuitivo.

Calkins apresenta lições sobre forma, cor, número, tamanho, desenho, escritura, tempo, som, leitura elementar, qualidade das coisas, qualidades, natureza e plano, do corpo humano e educação moral. O autor explicita uma ordem na qual os conteúdos devem ser ensinados. Segundo Calkins (1950), a ordem deve ser seguida para que haja um melhor aproveitamento pelo aluno, já que esta estabelece o que se deve ensinar primeiro e o que se deve seguir na ordem natural. As lições são enunciadas por passos, conforme as orientações do Programa de 1917 para o primeiro ano escolar. Porém, as lições de Desenho, ao contrário das indicações do programa sergipano, de "não começar por linhas", iniciam-se justamente pelo traçado das linhas. Orienta o manual no primeiro passo: "Desenhar linhas - ensine o mestre a desenhar linhas pela pedra em direções diferentes. Tracem-se linhas curvas, movendo só os dedos; linhas mais longas, movendo 
a mão pela munheca; linhas ainda mais compridas, movendo a mão, o braço até o cotovelo, e, quando mister, o ombro" (Calkins, 1950, p. 361).

As apropriações sergipanas, em função das fontes inventariadas, parecem não seguirem muito de perto as orientações do método de lições de coisas no que diz respeito às lições de Desenho do manual de Calkins traduzido por Barbosa.

De outra parte, o programa de Desenho de 1917 traz a presença de figuras geométricas para serem traçadas. Predomina o enfoque do desenho ao natural que, por sua vez, integra as normatizações paulistas a partir de 1905, na primeira reforma do século 20. A abordagem do desenho ao natural é mote de separação da matéria de Desenho e Geometria nos programas de São Paulo. O desenho natural rompe com os traçados de figuras geométricas como passo inicial para o ensino do Desenho: está em voga o desenho de objetos simples e naturais para a criança. O Desenho ocupa-se do real e a Geometria do abstrato. O programa sergipano parece conjugar esses dois enfoques, mesmo que priorizando o desenho ao natural.

\section{As normativas oficiais do Estado de Goiás: desenho, geometria, régua e compasso}

O Estado de Goiás é tema de pesquisa da Rubia-Mar Nunes Pinto no projeto Por uma teoria e uma história da escola primária no Brasil: investigações sobre a escola graduada (1870-1930), financiado pelo CNPq, sob a coordenação de Rosa Fatima de Souza. Com o título Escola primária na primeira república: tensões e distensões de um jogo de empurra, Pinto (2012) retrata o cenário do Estado no período de criação dos grupos escolares.

A figura central no processo de constituição dos grupos escolares é Alves de Castro, que assumiu o governo em 1917 e logo no ano seguinte implantou a reforma educacional que acarretou a criação de grupos escolares, bem como marcou o início de um período de reformas que perdurou até o final da Primeira República (Pinto, 2012).

A reforma de 1918 alterou o uso do tempo nas escolas primárias, os saberes e as formas de ensinar e avaliar. A modernidade pedagógica dos grupos escolares anunciouse também pelo novo método de ensino: a palavração e a sentenciação. O aprendizado concreto devia estimular a observação e a manipulação mediada pela intuição (Pinto, 2012). Nos anos de 1920 o crescimento no número de escolas foi significativo, de 21 escolas primárias em 1917 para 186 em 1930. Também se elevou o número de crianças que cursavam o ensino primário. A rede de grupos escolares, entretanto, pouco cresceu, enquanto a escola isolada manteve-se numericamente mais expressiva (Pinto, 2012).

De acordo com Pinto (2012), o modelo inspirador da reforma de 1918 foi o paulista, com alguma apropriação da experiência do Rio de Janeiro: "O desejo pela modernidade, entretanto, parece ter guiado os legisladores goianos mobilizando-se para a implantação de uma escola que se aproxima dos moldes da moderna forma escolar e, portanto, tipicamente urbana" (p. 325).

E em relação aos saberes de Desenho e Geometria? O que se pode apreender da análise dos programas de ensino antes e depois de 1918, marco da criação dos grupos escolares goianos? 
O programa do Estado de Goiás de $1893^{18}$ está organizado em três entrâncias que compõem as escolas de primeiras letras. A matéria que envolve os saberes em questão denomina-se Desenho Linear, participa nas três entrâncias, assim como não há referência à Geometria. Os conteúdos contemplados em Desenho Linear são geométricos, como linhas, ângulos, triângulos, círculo, desde a primeira entrância. Na segunda entrância encontra-se, ao final dos conteúdos, os primeiros exercícios com réguas, compasso, esquadro e transferidor e na terceira entrância a aproximação acontece por representação geométrica a traço. Vale ressaltar que há também outros conteúdos na matéria de Desenho Linear, para além das figuras geométricas, como desenho de ornato, de arquitetura, de máquinas.

O primeiro programa atenta para a presença dos instrumentos geométricos na matéria Desenho Linear, antes mesmo da nova estruturação do ensino advinda com os grupos escolares, ou seja, o Desenho Linear, presente de maneira forte em tempos de Império, se incumbe dos saberes de Geometria, a ponto de ser uma única matéria em questão e de incorporar práticas de construções geométricas.

Não foi possível encontrar o programa de 1918, marco da criação dos grupos escolares, mas dispõe-se do programa de $1925^{19}$. Geometria e Desenho é a rubrica de uma única matéria, presente nos quatro anos de ensino dos grupos escolares de Goiás. Os conceitos são, na sua grande maioria, geométricos, desde linhas, ângulos, triângulos, quadriláteros, círculos e figuras tridimensionais, como paralelepípedos, pirâmide, cilindro. Quanto aos traçados, no $1^{\circ}$ ano, a recomendação é "traçar linhas retas à mão livre", a partir do $2^{\circ}$ ano, as orientações incluem instrumentos, como "traçar linhas empregando régua e compasso". Já no $3^{\circ}$ ano, se observa: "Traçado da bissetriz de um ângulo, empregando-se régua e compasso" (Programa de Geometria e desenho, 1925). Ao final de cada programa há uma grade de horário para cada um dos anos. Nos dois primeiros anos, apesar da matéria do programa se denominar Geometria e Desenho, no horário menciona-se apenas Desenho e somente nos dois últimos anos a distribuição das matérias no horário é registrada como Geometria e Desenho.

Finalmente, o próximo programa inventariado é de 1930, que se configura como cópia do Programa de São Paulo de 1925. De imediato, o Desenho separa-se da Geometria e toma como método o desenho ao natural, espontâneo, em que as crianças devem desenhar o que imaginam e sentem, assim como objetos da natureza. A Geometria apresenta-se somente nos dois últimos anos, $3^{\circ}$ e $4^{\circ}$ anos, tendo nos dois primeiros uma nova matéria denominada Formas $^{20}$, que contempla, além de formas geométricas, a confecção de sólidos geométricos em argila e plastilina. Em Geometria, para o $3^{\circ}$ ano, encontram-se as mesmas observações de São Paulo: "Traçado da circunferência a mão livre e a compasso. Fazer um ângulo igual ao outro com compasso e transferidor. Traçado de perpendiculares com auxilio de régua, esquadro e compasso. Traçado de triângulos com instrumentos" (Programa de Geometria, 1930).

${ }^{18}$ Regulamento da Instrução Primária do Estado de Goiás. Aprovado pelo decreto n. 26, de 23 de dezembro de 1893. Assinado por José Ignacio Xavier de Brito e Arthur Napoleão Gomes Pereira da Silva.

19 O programa é oficializado pelo decreto n. 8.538, de 12 de fevereiro de 1925, da Secretaria dos Negócios do Interior e Justiça. Assinado por Miguel da Rocha Lima e Arthur da Silva Jucá.

${ }^{20}$ Um estudo mais aprofundado sobre a matéria Formas pode ser lido no texto $A$ constituição de uma nova matéria escolar no curso primário paulista: as formas, de Frizzarini, C. R. B. apresentado no $17^{\circ}$ Ebrapem, Vitória, ES, 2013. 


\section{As normativas oficiais do Estado do Rio Grande do Sul: desenho, geometria, régua e compasso}

A pesquisa de Luchese (2013) pretende problematizar a normatização que instaura um novo modelo escolar no Rio Grande do Sul, os colégios elementares. Ainda em desenvolvimento, resultados parciais foram apresentados no $7^{\circ}$ Congresso Brasileiro de História da Educação.

De acordo com Luchese (2013), o decreto n. 1.479, de 1909, modificou o programa de ensino complementar e criou os colégios elementares no Estado. Os colégios elementares significaram um novo modelo de organização da escola: seriada, com professor regente em cada classe, com a presença de diretor e secretaria. $O$ estudo ressalta que os colégios elementares do Rio Grande do Sul inauguram um novo modelo escolar, denominado no restante do Brasil como grupo escolar.

Os colégios elementares foram organizados, em 1909, em três classes, com duas seções cada, sendo que cada seção corresponde a um ano letivo escolar, o que totaliza seis anos de escolarização (Luchese, 2013). Nota-se que o Estado do Rio Grande do Sul apresenta particularidades e distingue-se dos Estados até então analisados desde a designação, organização e tempo escolar. O estudo de Luchese (2013), talvez por estar em desenvolvimento, não faz referência ao modelo paulista dos grupos escolares e de relações de proximidade entre os dois Estados.

Quanto aos saberes de Desenho e Geometria toma-se para examinar dois programas, o de 1899 e de 1910, de modo a identificar mudanças ou permanências do nosso objeto de investigação - construções com régua e compasso - na implantação do novo modelo escolar do Rio Grande do Sul.

O decreto de $1897^{21}$ organizou o ensino das escolas elementares em três classes e cada classe em duas seções. Nele estão presentes: sistema métrico precedido do estudo de geometria pratica (tachymetria) e desenho. A apresentação e descrição do programa para cada um dos saberes é oficializado pelo decreto n. $237^{22}$ em 1899.

O Desenho se inicia desde a $1^{a}$ classe e, nas suas seções, propõe o traçado de linhas e figuras fáceis, compostas de linhas retas, sem auxílio da régua. $\mathrm{Na} 2^{\mathrm{a}}$ classe o programa de desenho orienta o "traçado de figuras, acompanhando o desenvolvimento as lições de geometria, desenho de objetos de simples reprodução" (decreto n. 237 ${ }^{23}$, 1899). Ao mesmo tempo se inicia o estudo da Geometria, que engloba linhas, posições de retas, ângulos, triângulos, quadriláteros. Finalmente, na $3^{a}$ classe, as orientações são de "Traçados de figuras, acompanhando e desenvolvendo as lições de geometria. Reprodução de todo o desenho geométrico com emprego de régua, compasso e tiralinhas e transferidor. Desenho de paisagens" (decreto n. $237^{24}$, 1899). Nesta última classe a Geometria ocupa-se do estudo das circunferências, áreas, conhecimento prático dos sólidos geométricos, volumes.

Uma vez mais fica evidente a proximidade entre Desenho e Geometria no ensino elementar do Rio Grande do Sul. Como duas disciplinas distintas, não há na legislação

${ }^{21}$ Decreto n. 89, de 2 de fevereiro de 1897. Assinado por Julio Prates de Castilhos. Dr. João Abbott.

22 Decreto n. 239, de 5 de junho de 1899. O programa é assinado por Manoel Pacheco Prates.

${ }^{23}$ Decreto n. 239, de 5 de junho de 1899. O programa é assinado por Manoel Pacheco Prates.

${ }^{24}$ Decreto n. 239, de 5 de junho de 1899. O programa é assinado por Manoel Pacheco Prates. 
uma designação específica: o ensino de Desenho precede ao de Geometria e se inicia com traçado de linhas retas, à mão livre. A partir da $2^{a}$ classe, sem entrar em detalhes, o Desenho acompanha as lições de Geometria, ou seja, é suporte e ferramenta para o estudo de Geometria. No estágio final, sem se desligar das lições de Geometria, incorpora o uso de régua e compasso.

É preciso ainda destacar que a terminologia tachymetria, empregada como sinônimo de Geometria Prática, é uma expressão presente no parecer de Rui Barbosa, de 1882, no qual ele a define como sendo a "concretização da geometria, é o ensino da geometria pela evidência material, a acomodação da geometria às inteligências mais rudimentares: é a lição de coisas aplicadas à medida das extensões e volumes" (Barbosa, 1947, p. 290). Desta forma, reafirma-se o papel emblemático do parecer de Rui Barbosa, que serviu como referência para os republicanos nos debates e proposições da educação (Souza, 2009).

Com a implantação dos colégios elementares, um novo programa foi anunciado no decreto n. $1.575^{25}$, de 1910. As denominações das matérias permanecem as mesmas, Desenho e Geometria Prática, assim com a distribuição nas três classes: o Desenho tem início desde a $1^{\text {a }}$ classe e a Geometria Prática a partir da $2^{a}$ classe. A descrição dos conteúdos de Geometria praticamente não se altera, assim como conserva a mesma organização e disposição do programa de 1899.

As pequenas modificações se evidenciam no Desenho, que continua conjugando desenhos de objetos como corpos, garrafas, flores, frutos com os objetos geométricos. $\mathrm{Na}$ primeira classe indica-se: "traçar sem auxílio da régua linhas retas, horizontais, verticais e sem o auxílio de medidas dividir retas em partes iguais. Desenho de quadrados e retângulos, divisão destas figuras em partes iguais" (Programa de 1910). Na $2^{a}$ classe, retoma-se o "traçado de figuras geométricas acompanhando as noções de geometria" e na $3^{a}$ classe "resolver problemas mais simples de desenho linear com o auxílio da régua e compasso" (Programa de 1910). Em síntese, o programa de 1910 acentua e detalha ainda mais as figuras geométricas a serem traçadas em Desenho, num primeiro momento à mão livre e, ao final do ensino, com o uso de instrumentos. Convivem bem as indicações de traçados com instrumentos e desenho de objetos naturais, sem necessidade de o Desenho romper com a Geometria e as construções geométricas com régua e compasso.

É possível dizer que, em relação aos saberes de Geometria e de Desenho, a nova estruturação do ensino primário, com a criação dos colégios elementares, no Estado do Rio Grande do Sul, não provocou alterações significativas. De outra parte, também não é preciso esperar a nova organização de ensino para a incorporação das novas propostas pedagógicas, elas estão presentes desde o final do século 19 , mesmo sem o novo modelo escolar, haja vista a organização dos conteúdos distribuídos nas classes e seções desde o programa de 1899.

\footnotetext{
${ }^{25}$ Decreto n. 1575, de 27 de janeiro de 1910. Leis, decretos e atos do governo do Estado do Rio Grande do Sul do ano de 1910, p. 196-212 (Corsetti, 1998). 


\section{Considerações finais}

Não é demais reafirmar que, no presente artigo, procurou-se realizar um exercício preliminar de investigação comparativa em história da educação matemática, de modo a tentar captar como foram construídas representações para orientar oficialmente práticas pedagógicas dos ensinos de Geometria e Desenho. Para tanto, o tema de estudo centrouse no uso de instrumentos de construção, como régua e compasso, nas indicações prescritivas promulgadas no final do século 19 e início do século 20 e, mais especificamente, na implementação dos novos modelos de escola primária.

As fontes legislativas, dos Estados de Minas Gerais, Sergipe, Goiás e Rio Grande do Sul, são cotejadas com os estudos realizados no Estado de São Paulo, considerado modelo para a constituição dos grupos escolares. Em relação aos saberes de Geometria e Desenho muitas são as apropriações das propostas paulistas e, assim como em São Paulo, evidencia-se uma aproximação entre os dois saberes, sendo possível conjugar desenhos de objetos naturais e traçados de figuras geométricas com o uso de régua e compasso. Minas Gerais e Goiás designam uma única rubrica de matéria por Desenho e Geometria e incorporam a régua e compasso. Em Sergipe apontam-se indícios, porém não é possível identificá-los, e no Rio Grande do Sul vê-se o programa explicitar os dois enfoques sem qualquer problema.

Vale ainda destacar que, apesar da constituição do modelo de grupo escolar ser mais tardia nos Estados de Sergipe, Goiás e Rio Grande do Sul, as incorporações das propostas do método de lições de coisas nos programas de Desenho e Geometria ocorreram desde o final do século 19 e não aguardaram a nova configuração do ensino primário para as normatizações. Minas Gerais, que somente apresentou nas normatizações a Geometria e o Desenho após a implantação dos grupos escolares, necessita ser investigado. Igualmente importante é a circulação e apropriação do parecer de Rui Barbosa nas orientações, mesmo que em alguns Estados, como Sergipe, elas apontem discordâncias comparativamente ao manual por ele traduzido.

Em síntese, pelo estudo parcial de normatizações para o ensino primário pode-se dizer que as construções utilizando régua e compasso participaram de práticas normativas no ensino primário, em matérias de Desenho, Desenho Linear, Geometria, Geometria Prática, no recorte geográfico dos Estados elegidos. Infere-se, ainda, que construções com instrumentos geométricos podem representar práticas pedagógicas para o ensino de Geometria e de Desenho no ensino primário do período da Primeira República, para além do Estado de São Paulo, tido como modelo. Evidencia-se a circulação e apropriação das recomendações para o emprego de régua e compasso e, desta forma, estudos mais aprofundados precisam ser desenvolvidos de modo a compreender as finalidades da construção geométrica como elemento constitutivo na representação nacional sobre o passado do ensino de Geometria na escola primária.

Por fim, a consulta de fontes disponibilizadas num repositório virtual, como o que está sendo oportunizado pelo projeto em desenvolvimento, possibilita novos subsídios para a produção de uma história comparada. Há necessidade, porém, de não se descuidar do alerta de Souza (2013) para os perigos do reducionismo da mera reunião de dados singulares ou a justaposição de realidades espaciais contíguas, considerando que o contributo maior da história comparada pode estar no diálogo estabelecido entre as histórias regionais, identificando contrastes, conexões e aproximações. 


\section{Referências}

ARAUJO, José Carlos de Souza. Republicanismo e escola primária nas mensagens dos presidentes de Estado de Minas Gerais (1891-1930). ARAÚJO, José Carlos de Souza; SOUZA, Rosa Fátima; PINTO, Rubia-Mar Nunes (orgs.). Escola primária na primeira república (1889-1930): subsídios para uma história comparada. Araraquara: Junqueira \& Marin, 2012, p. 100-150.

BARBOSA, Rui. Reforma do ensino primário e várias instituições complementares da instrução pública. Obras completas, v. X, tomo I-IV. Rio de Janeiro: Ministério da Educação e Saúde, 1947.

CALKINS, Norman Allison. Primeiras lições de coisas. Rio de janeiro: Ministério da Educação e Saúde, 1950. [Volume XIII, tomo I das Obras completas de Rui Barbosa).

CORSETTI, Berenice. Controle e ufanismo: a escola pública no Rio Grande do Sul (1899/1930). Hist. Educ. (Online), Porto Alegre, n. 4, 1998, p. 57-75.

FREIRE, Olavo. Primeiras noções de geometria pratica. Rio de Janeiro: Francisco Alves \& $\mathrm{C}^{\mathrm{ia}}, 1907$.

FRIZZARINI, Claudia Regina Boen. A constituição de uma nova matéria escolar no curso primário paulista: as formas. EBRAPEM, 17, 2013. Anais ... Vitória, 2013.

GOIÁS. Regulamento da Instrução Primária do Estado de 23 de Dezembro de 1893, GO. Aprovado por decreto n. 26, de 23 de dezembro de 1893, Goyaz. Assinado por José Ignacio Xavier de Brito e Arthur Napoleão Gomes Pereira da Silva. Disponível em: $<$ https://repositorio.ufsc.br/handle/123456789/99658>. Acesso em 10 out., 2013.

GOIÁS. Regulamento e Programa de Ensino dos Grupos Escolares do Estado de Goiás, 1925. Assinado por Arthur da Silva Jucá. Disponível em: <https://repositorio.ufsc.br/handle/123456789/99993>. Acesso em 10 out., 2013.

GOIÁS. Programa de Ensino das Escolas Primárias, 1930. Assinado por Mario de Bulhões. Disponível em: <https://repositorio.ufsc.br/handle/123456789/99660>. Acesso em 10 out., 2013.

LEME DA SILVA, Maria Célia. Desenho e geometria na escola primária: um casamento duradouro que termina com separação litigiosa. Hist. Educ. (Online), Porto Alegre, v. 18, n. 42,2014 , p. 61-73.

LUCHESE, Terciane Ângela. Da prescrição à realização: os colégios elementares como um novo modelo de escola primária no Rio Grande do Sul (1909-1927). CONGRESSO BRASILEIRO DE HISTÓRIA DA EDUCAÇÃO, 7, 2013. Anais ... Cuiabá, 2013, p. 1-14.

NASCIMENTO, Jorge Carvalho. Notas para uma reflexão acerca da escola primária republicana em Sergipe (1889-1930). In: ARAÚJO, José Carlos de Souza; SOUZA, Rosa Fátima; PINTO, Rubia-Mar Nunes (orgs.). Escola primária na primeira república (18891930): subsídios para uma história comparada. Araraquara: Junqueira \& Marin, 2012, p. 210-245.

PINTO, Rubia-Mar Nunes. Escola primária em Goiás na primeira república: tensões e distensões de um jogo de empurra. In: ARAÚJO, José Carlos de Souza; SOUZA, Rosa Fátima; PINTO, Rubia-Mar Nunes (orgs.). Escola primária na primeira república (18891930): subsídios para uma história comparada. Araraquara: Junqueira \& Marin, 2012, p. 300-328. 
RIO GRANDE DO SUL. Decreto n. 89, de 2 de fevereiro de 1897. Assinado por Júlio Prates de Castilhos e João Abbott. Disponível em: <https://repositorio.ufsc.br/handle/ 123456789/100091>. Acesso em 10 out., 2013.

RIO GRANDE DO SUL. Decreto n. 239, de 5 de junho de 1899. Assinado por A. A. Borges de Medeiros e João Abbott. Disponível em: <https://repositorio.ufsc.br/handle/ 123456789/100095>. Acesso em 10 out., 2013.

SANTOS, Ivanete Batista. Em busca do ensino de aritmética, geometria e desenho nos grupos escolares sergipanos (1911-1935). CONGRESSO BRASILEIRO DE HISTÓRIA DA EDUCAÇÃO, 7, 2013. Anais ... Cuiabá, 2013.

SÃO PAULO. Trecho do decreto n. 248, de 26 de julho de 1894. Aprovado por Bernardino de Campos e assinado pelo Dr. Cesário Motta Junior. Disponível em: <https://repositorio.ufsc.br/handle/123456789/99544>. Acesso em 10 out., 2013.

SÃO PAULO. Trecho do decreto n. 1281, de 24 de abril de 1905. Aprovado por Jorge Tibiriçá e assinado por J. Cardoso de Almeida. Disponível em: <https://repositorio.ufsc.br/handle/123456789/99554>. Acesso em 10 out., 2013.

SÃO PAULO. Trecho do decreto n. 2.944, de 8 de agosto de 1918. Aprovado por Altino Arantes e assinado por Oscar Rodrigues Alves. Disponível em: <https://repositorio.ufsc.br/handle/123456789/99555>. Acesso em 10 out., 2013.

SÃO PAULO. Trecho do decreto n. 3.356, de 31 de maio de 1921. Aprovado por Washington Luiz Pereira de Sousa e assinado por Alarico Silveira. Disponível em: <https://repositorio.ufsc.br/handle/123456789/99556>. Acesso em 10 out., 2013.

SÃO PAULO. Trecho do programa de 19 de fevereiro de 1925. Aprovado pelo secretário de Estado dos Negócios do Interior, José Manuel Lobo. Disponível em: <https://repositorio.ufsc.br/handle/123456789/99651>. Acesso em 10 out., 2013.

SCHUBRING, Gertz. A produção internacional em história da educação matemática. ENCONTRO NACIONAL DE PESQUISA EM HISTÓRIA DA EDUCAÇÃO MATEMÁTICA, $1^{\circ}, 2012$. Anais ... Vitória da Conquista, 2012.

SERGIPE. Decreto n. 563, de 12 de agosto de 1911. Assinado por José Rodrigues da Costa Doria. Disponível em: <https://repositorio.ufsc.br/handle/123456789/103582>. Acesso em 10 out., 2013.

SERGIPE. Programma para o curso primário nos grupos escolares e escolas isoladas, 1917. Assinado por Helvecio Andrade. Disponível em: <https://repositorio. ufsc.br/handle/123456789/103591>. Acesso em 10 out., 2013.

SOUZA, Rosa Fátima. Alicerces da pátria: história da escola primária no Estado de São Paulo (1890-1976). Campinas: Mercado de Letras, 2009.

SOUZA, Rosa Fátima. Cruzando fronteiras regionais: repensando a história comparada da educação em âmbito nacional. REUNIÃO ANUAL DA ANPED, 36, 2013, Goiânia. Anais... Goiânia, 2013.

SOUZA, Rosa Fátima (org.). Fontes para o estudo da história da escola primária no Brasil (1889-1930). Araraquara: Unesp/CNPq, 2011. 1 DVD.

TOLOSA, Benedito Maria. Primeiras lições de desenho. In: A eschola publica - ensaio de pedagogia prática. Typographia Paulista. São Paulo, 1895. Disponível em: $<$ http://www.arquivoEstado.sp.gov.br/educacao/publicacoes.php>. Acesso em: 30 nov., 2011. 
VALENTE, Wagner Rodrigues. Tempos de império: a trajetória da geometria como um saber escolar para o curso primário. Revista Brasileira de História da Educação, v. 12, 2012, p. 73-94.

VALENTE, Wagner Rodrigues. Oito temas sobre história da educação matemática. Rematec, v. 8, n. 12, 2013, p. 22-50.

MARIA CÉLIA LEME DA SILVA é doutora em Educação pela PUCSP. Realizou estágio pós-doutoral na Universidade Nova de Lisboa em História da Educação Matemática. Atualmente é professora na Universidade Federal de São Paulo, campus Diadema, e pesquisadora do Ghemat.

Endereço: Rua Arthur Ridel, 275 - 09972-270 - Diadema - SP - Brasil.

E-mail: mcelialeme@gmail.com.

Recebido em 3 de abril de 2014.

Aceito em 1을 de julho de 2014. 